\begin{tabular}{|l|l|l|}
\hline \multicolumn{2}{|c|}{ PublisherInfo } \\
\hline \hline PublisherName & $:$ & BioMed Central \\
\hline \hline PublisherLocation & $:$ & London \\
\hline \hline PublisherImprintName & $:$ & BioMed Central \\
\hline
\end{tabular}

\title{
Reducing MAP does not affect cerebral blood flow
}

\begin{tabular}{|l|l|l||}
\hline \multicolumn{2}{|c||}{ ArticleInfo } \\
\hline \hline ArticleID & $:$ & 4074 \\
\hline \hline ArticleDOI & $:$ & $10.1186 /$ ccf-1999-1081 \\
\hline \hline ArticleCitationID & $:$ & 1081 \\
\hline \hline ArticleSequenceNumber & $:$ & 11 \\
\hline \hline ArticleCategory & $:$ & Paper Report \\
\hline ArticleFirstPage & $:$ & 1 \\
\hline \hline ArticleLastPage & $:$ & 4 \\
\hline \hline & & RegistrationDate : 1999-7-23 \\
\hline ArticleHistory & $:$ & OnlineDate \\
\hline \hline ArticleCopyright & $:$ & Current Science Ltd1999-7-23 \\
\hline \hline ArticleGrants & $:$ & \\
\hline \hline ArticleContext & $:$ & 130541111 \\
\hline \hline
\end{tabular}




\section{Keywords}

Cerebral blood flow, intracerebral hemorrhage, mean arterial pressure

\section{Comments}

This study aimed to address an important clinical situation (seen in general as well as neurosurgical intensive therapy units) in a logical and methodical manner. However, the model of intracerebral hemorrhage has limitations in the application of results to the human situation when the insult of intracerebral hemorrhage is often associated with other injuries to the brain or other organs. The model used had hemorrhage induced by the discreet injection of a fixed volume of blood.Even taking account of the small numbers of subjects used, the study does suggest that the controlled use of antihypertensives in the initial treatment of intracerebral hemorrhage may limit the size of hemorrhage with no deleterious effects on the surrounding areas of brain.

\section{Introduction}

Following intracerebral hemorrhage there is often a period of systemic hypertension. The treatment of acute hypertension at this time is controversial. Previous animal studies have shown a reduction in regional cerebral blood flow and it has been hypothesised that autoregulation is impaired in the region around the hematoma due to local ischemia and acidosis. It has been thought that treatment of systemic hypertension may worsen areas of ischemia.

The dilemma arises with evidence that in one-third of patients with spontaneous intracerebral hematoma, the lesion expands in the few hours after the initial injury. This can lead to clinical deterioration and death. Such further expansion may be reduced by reduction in blood pressure.

\section{Aims}

To determine the effect of a reduction in mean arterial pressure (MAP) on regional cerebral blood flow and intracranial pressure (ICP) in animal models of intracerebral hemorrhage. The authors aimed to provide a rational basis for blood pressure management in intracerebral hemorrhage. 


\section{Methods}

Following approval by the institutional animal care and use committee, 18 mongrel dogs of both genders were anesthetised and ventilated with a standard tidal volume and ventilatory frequency. Mean arterial pressure was monitored throughout with an intra-arterial catheter. An intracerebral catheter was inserted in a standard position through a burr hole and autologous blood infused [either $2.8 \mathrm{ml}$ (group A) or $4.4 \mathrm{ml}$ (group B)] over 15 to $20 \mathrm{~min}$. Six animals who acted as controls, underwent needle placement without infusion of blood. Intracranial pressure was monitored using a spinal needle in the cisterna magna and a left ventricular catheter inserted for measurement of cerebral blood flow (CBF).Cerebral blood flow was measured by six different radiolabelled microspheres injected into the left ventricular catheter. Each type of radiolabelled microsphere were injected at various time points during the study and radioactivity measured at the end of the study. The dogs were given an intravenous dose of $2.5 \mathrm{mg}$ labetalol and their CBF monitored again. At the end of the study the animals were sacrificed and their brains prepared. Regional blood flow was measured in grey and white matters, caudate, thalamus, upper and lower brain stem, and cerebellum on right and left sides separately. Zones within $5 \mathrm{~mm}$ and more than $5 \mathrm{~mm}$ from the hematoma were identified and regional blood flow measured.

\section{Results}

Mean arterial pressure and ICP were similar in all three groups before administration of hematoma. Groups A and B had an immediate rise in ICP associated with hematoma injection. Values for ICP remained significantly elevated at 45 and 90 min after injection of blood and were more prominent in group B. Administration of labetalol produced a significant decrease in MAP in all three groups. There was no significant change in ICP after reduction of MAP in all three groups.

There were no significant differences in regional cerebral blood flow, between the hematoma and controls in any of the identified zones in the ipsilateral or contralateral hemispheres, before or after introduction of blood.

\section{Discussion}

The authors were unable to show any clear evidence of ischemic area around the hematoma in the acute period following intracerebral hemorrhage. In addition they showed that there was no change in regional cerebral blood flow after lowering of blood pressure with labetalol. In the animal model used, despite the elevated ICP, reduction of MAP was not associated with changes in the immediate and distant surrounding areas of the hematoma. There was no observed increase in ICP with a reduction in MAP, while the cerebral perfusion pressure was maintained at $>65 \mathrm{mmHg}$. The authors accept that their study only examines the immediate changes and not the longer term effects of intracerebral hemorrhage. 


\section{References}

1. Qureshi AI, Wilson DA, Hanley DF, Traystman RJ: Pharmacologic reduction of mean arterial pressure does not adversely affect regional cerebral blood flow and intracranial pressure in experimental intracerebral hemorrhage. Crit Care Med. 1999, 27: 965-971.

This PDF file was created after publication. 